Article

\title{
Systems Thinking Approach to Sustainable Performance in RAMSAR Sites
}

\author{
Jacqueline Y. Sánchez-García ${ }^{1}$, Ana Gabriela Ramírez-Gutiérrez ${ }^{2}$, Juan E. Núñez-Ríos ${ }^{1, *(\mathbb{D} \text {, }}$ \\ Pedro Pablo Cardoso-Castro ${ }^{3}$ (D) and Omar G. Rojas ${ }^{1}$ (D) \\ 1 Escuela de Ciencias Económicas y Empresariales, Universidad Panamericana, Álvaro del Portillo 49, \\ Zapopan, Jalisco 45010, Mexico; jsanchezg@up.edu.mx (J.Y.S.-G.); orojas@up.edu.mx (O.G.R.) \\ 2 ESDAI, Universidad Panamericana, Álvaro del Portillo 49, Zapopan, Jalisco 45010, Mexico; \\ agramirez@up.edu.mx \\ 3 School of Business and Law, Leeds Beckett University, Leeds LS13HU, UK; \\ P.P.Cardoso-Castro@leedsbeckett.ac.uk \\ * Correspondence: jnunezr@up.edu.mx
}

Received: 16 October 2019; Accepted: 14 November 2019; Published: 17 November 2019

\begin{abstract}
This article explores and validates the integrated use of the viable system model (VSM) and the partial least squares path modeling (PLS-PM) approach to assess the sustainable management of RAMSAR sites carrying out economic activities. This work adopts a systems-thinking approach integrating systemic methodologies in three phases: (1) the VSM was first used to develop a conceptual model of the organisational problem; (2) PLS-PM was used to propose a construct to outline a solution, as well as to statistically validate the relationships proposed in the conceptual model; finally, (3) through the VSM, the relationships between actors were rethought in order to promote sustainable performance. The results obtained suggest that the joint use of VSM and PLS-PM is an effective approach that aids in the identification of relational and structural pathologies affecting the observed RAMSAR systems. It also proved useful to suggest that relationships can lead to the sustainable performance of the sites under study. It should be noted that the framework of systemic tools is constrained in its application to the organisational domain: assessing two RAMSAR areas in Mexico. Methodologically, this is the first application of the integrated use of VSM and PLS-PM to analyse the management and viability/sustainability of RAMSAR areas from an organisational perspective, opening a new avenue for the analysis and optimisation of management of such areas. This study provides tools to support actors and academics related to RAMSAR sites and opens up a discussion on how to rethink the organisational interactions in order to improve RAMSAR sites' adaptive capabilities.
\end{abstract}

Keywords: sustainability; organisational cybernetics; systems thinking; partial least squares path modeling; viable system model

\section{Introduction}

Sustainability continues to be a priority for different organisations. For example, protected natural areas, such as RAMSAR sites, are subject to cross-cutting policies aimed at mitigating biodiversity loss for future use and at developing projects that integrate community groups, organisations, service providers and government institutions [1]. The Ramsar Convention is an intergovernmental treaty that provides the framework for the conservation and wise use of wetlands and their resources. The convention uses a broad definition of wetlands, it includes all lakes and rivers, underground aquifers, swamps and marshes, wet grasslands, peatlands, oases, estuaries, deltas and tidal flats, 
mangroves and other coastal areas, coral reefs, and all human made sites such as fishponds, rice paddies, reservoirs and saltpans [2].

According to the Ramsar Convention [2], wetlands are a key component of sustainable development, because they supply all the fresh water, provide welfare and safety to people who live in or near them, they are amongst the world's most productive environments, and provide a wide array of benefits. In addition, wetlands provide at least US $\$ 4.9$ trillion worth of services annually. However, global wetland losses and degradation continue worldwide, it is estimated that between $64 \%-71 \%$ of wetlands extended losses in the $20^{\text {th }}$ century [3]. Currently, there are 170 countries as part of the convention, 2372 designated sites covering 253,603,511 hectares (ha). The three countries with most RAMSAR sites are: United Kingdom (175 Ramsar Sites, 1,283,040 ha), Mexico (142 Ramsar Sites, 8,657,057 ha) and Spain (75 Ramsar Sites, 304,564 ha) [4]. Additionally, a constant difficulty in this regard is balancing the operationalisation of strategies that support the viability of productive activities, without neglecting the impact on the natural resources where they operate.

According to Bansal and DesJardine [5] and Wan Mohamed Radzi et al. [6], the problems related to the sustainable performance of organisations operating in protected natural areas are increasingly critical so the modality of operating and relating to other organisations has gained relevance given that their interactions could disturb or endanger their environment [7]. In this context, Gao et al. [8] indicate that different efforts such as corporate social responsibility (CSR), corporate sustainability (CS) or environmental management (EM), have been made to help organisations in these sites become sustainable; however, the world travel \& tourism council (WTTC) [9] agreed that there are still large areas of opportunity, especially in organisational schemes, to support organisations in these areas (e.g., wetlands) to reduce their impacts and be viable.

Within this context, the national commission of protected areas (CONANP, for its acronym in Spanish) [10] indicates that there are some RAMSAR sites that in their dynamics consider economic activities which are developed by the communities that inhabit the area. It also highlights that these activities face continuing challenges in terms of the design and operation of productive projects that seek both economic benefits and social well-being of communities. According to Butler and Adamowski [11], RAMSAR sites mainly face problems between environmental and economic factors, so the management, rational use and conservation of their resources should consider a participatory and multisectoral perspective. Within this framework, Demirel and Kesidou [12] and the WTTC [13] consider that the factors that most affect the balance between sustainable operations, the reduction of the impact on the environment and the economic stability of service providers are: the lack of coordination between the different actors involved in the management of these types of sites, the fact that agreements and the implementation of strategies are voluntary, and the absence of control mechanisms.

Given the above, it is necessary to consider organisational context and frame RAMSAR interactions through a perspective that allows designing operational structures that, at their core, provide equilibrium and sustainability. In this sense, the objective of this article is to propose an organisational alternative for RAMSAR sites that carry out economic activities (such as tourism) to support the balance between (commercial) operations and environmental impact. Therefore, the ideas developed in this work are limited to the organisational domain and have as their application context the 1321 and 1819 RAMSAR sites located in Oaxaca, Mexico. To fulfil this purpose, the following particular objectives were established: a) identify problematic relationships of the organisations under study; b) propose a conceptual model based on the functions of the viable system model (VSM); c) estimate the validity of the construct using partial least squares path modeling (PLS-PM); d) to develop an optimized organisational arrangement inspired on the VSM adjusted for the systems(s) under study.

\section{Literature Review}

This section is intended to review the situation reported on the subject of sustainable management and to identify gaps concerning the perspectives in which it has been addressed. There are several works on sustainability management, mainly from environmental and social perspectives. The bibliometric 
search was carried out in SCOPUS ( academic bibliographic database) using "sustainability and systems thinking" as descriptors, considering the following search strategy: [("sustainable" OR "sustainability" OR "wetland" OR "site RAMSAR") AND TITLE-ABS-KEY("organisation" OR "business" OR "enterprise" OR "management") AND TITLE-ABS-KEY ("partial least square" OR "PLS" OR "predictive models" OR "structural equation modelling"))] in titles, abstracts and keywords. On the inclusion and exclusion criteria: articles included were those in which the scope considered the sustainable operations or systemic method in RAMSAR sites, without restrictions about countries and published from 2010-2019 and mostly in English. Articles dealing only with theoretical aspects were excluded. This resulted in a total of 80 articles, and after applying the exclusion criteria, only 40 contributions were obtained. Figure 1, shows the relationships and echo between these articles considering the approach applied by the authors (To design this figure, a node and edge list were generated in CSV format based on the information collected from Scopus. Then, these CSV files were processed in Rstudio using the igraph package and to present it, order by components was used as a plotting option). It should be noted that each document can be related to a contribution as shown in the network scheme. These relationships were established based Romero-García et al. [14] to generate an overview of the type of treatment that has been given to a given problem.

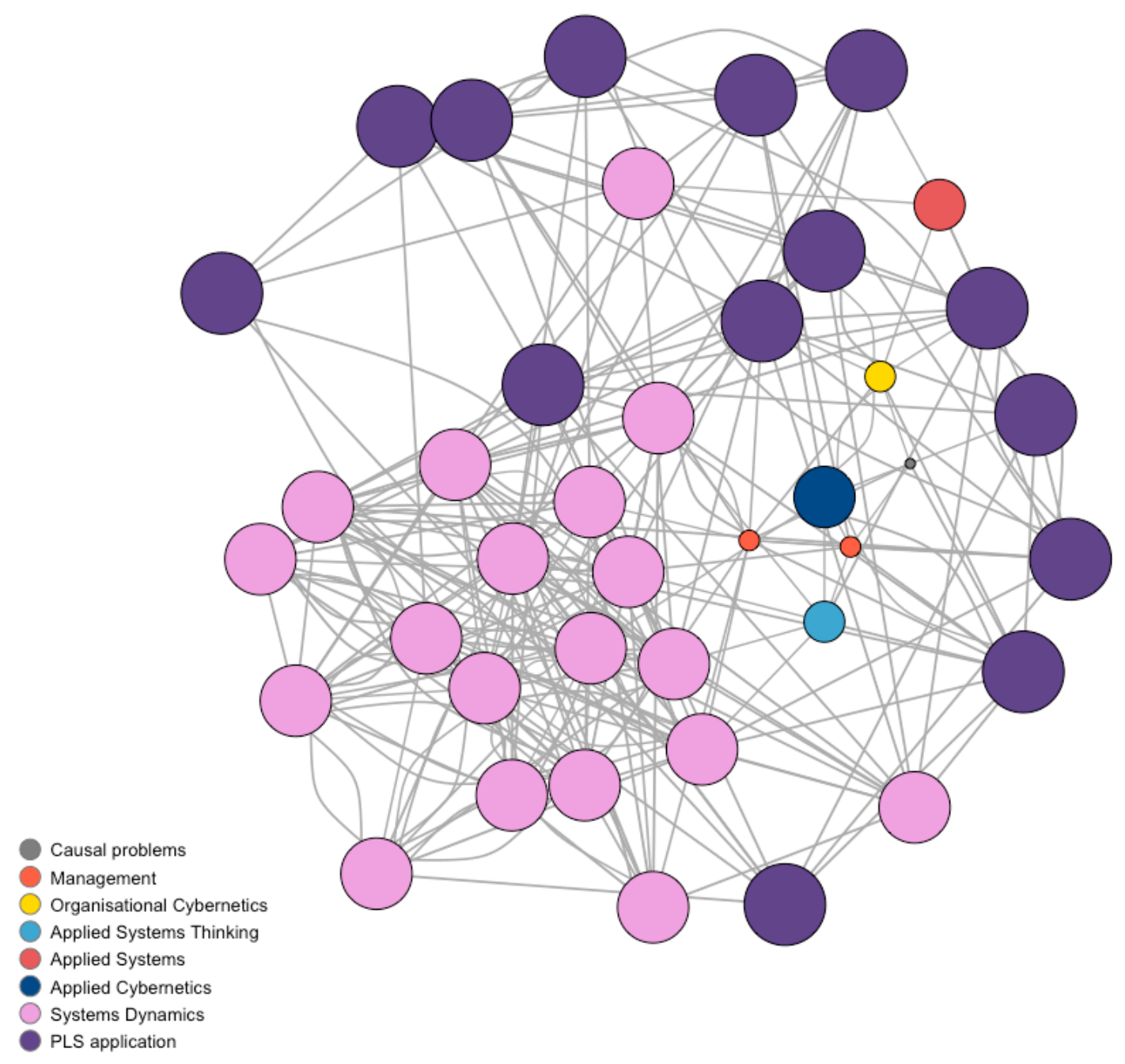

Figure 1. Network of approaches to problems related to sustainability. 
From Figure 1, it is apparent that the study of sustainability is considered as relevant and not only limited to environmental issues but also to the participation and impact generated by organisations. Considering the above ideas, authors such as Bansal and DesJardine [5], Banson et al. [15], Van Dyk and Pretorius [16], Fiksel [17]; Haywood et al. [18] and Nikolaou [19], stress the need to generate contributions under a comprehensive perspective that seeks short-term interventions and long-term improvements. Under this guidance, some contributions explore the application of systemic tools to reinforce the ability to meet their future needs. However, Laszlo [20] establish that one of the recurrent limitations, in different works, corresponds to the challenge of how to guide the participation and co-creation of adaptive and transformative processes in an organisation.

According to Fiksel [17], leading an organisation to a steady-state equilibrium requires structural changes that affect crucial aspects, such as the supply chain or the management of operations, in order to remain in a highly competitive environment and seek to ensure the life cycle of an organisational system. On this, Nikolaou [19] states that any organisation that does not adapt, at least, aspects such as costs, operations, management, and even reputation, faces the risk of disappearing in the face of problems related to sustainability. In this line of ideas, Haywood et al. [18] converge in mentioning that moving towards sustainability, demands the coherent relationship of multiple actors and regulatory mechanisms that support change, partially or in the whole system.

Concerning the expressed ideas, the works of Aguayo and Eames [21], Boyle and Michell [22] and McCool [23] suggest that the human factor, and its awareness, are essential to achieve sustainable organisational changes. In this regard, the socio-ecological approach is considered a pertinent way to lead a group towards learning and propitiating a comprehensive integration of social, environmental, economic, and institutional dimensions of sustainability, especially in emerging countries. Under this approach, some authors have tried to rethink community participation and commitment and include it as a fundamental part of the change processes. This links with ideas put forward by Barile and Saviano [24] who consider that an alternative response to sustainability problems can be found through the application of cybernetics or organisational cybernetics, for example, using the VSM since, in essence, it considers viability and sustainability supporting decision making for the survival of a system in a complex environment [25]. Complementarily, Nikolaou [19], Bautista [26], Song et al. [27] and Wei [28] emphasise the relevance of the application of system dynamics (SD), in order to understand the behaviour of an organisational system and evaluate the possible impacts that some aspects of the environment can generate, such as social constraints, in terms of learning and response capabilities. It is considered pertinent to mention that perspectives that address causal relationships, such as SD, causal problems and PLS-PM, substantially improve the models to support decision-making by studying the possible effects of the interaction of different variables.

Thus, statistical analysis is highlighted in particular by means of PLS-PM, because it has been used to study multiple factors such as how financial resources [29,30], intellectual capital [31,32], and supply chain [17,33-35], influence in sustainability. Also, from a causal perspective, Butler and Adamowski [11] emphasise that interventions based on group modelling can engage stakeholders with the consequence of sustainability. However, these proposals are limited because they do not consider aspects that, from the management's theory perspective, should be reinforced such as operations, management, resources and capacities aligning with the strategy to respond to the restrictions and expectations of sustainable management [22,36]. Considering this, it can be inferred that, although the application of PLS-PM approaches has been significant, efforts have focused on explanation or prediction, and the aspects of integration and operationalisation at a real level have been neglected in order to contribute to social development [21,37-39].

Based on the above, it is apparent that the current literature suggests an important gap concerning the approach to RAMSAR problem areas that include economic activities. Also, it was identified that the most common approaches to deal with problems related to sustainability are PLS-PM or SD. However, few interventions or proposals were found that consider methodological complementarity, for example, the joint use of the soft systems approach or VSM with PLS-PM. 


\section{Research Methodology}

The problems of RAMSAR sites can be framed in a fuzzy context in which multiple components interact that require integral perspectives. Based on this, the systemic method was used to articulate the ideas in this study; it is considered adequate since it addresses three necessary and complementary components of socio-ecological systems: relationships, structure and functions [40,41]. Additionally, this method seeks a synthesis between positivist, naturalist, and critical research methods by providing flexibility to articulate theoretical, methodological, and practical components to study complex problems. It is, therefore, possible to integrate within this framework the VSM (Figure 2) proposed by Stafford Beer [42] and the PLS-PM, to propose an option for improvement. In order to justify the selection of methodological tools, Warfield's $[43,44]$ domain of science model was taken as a reference, which establishes that the unitary perspective is not sufficient to address a problem with pluralistic and structuralist characteristics.

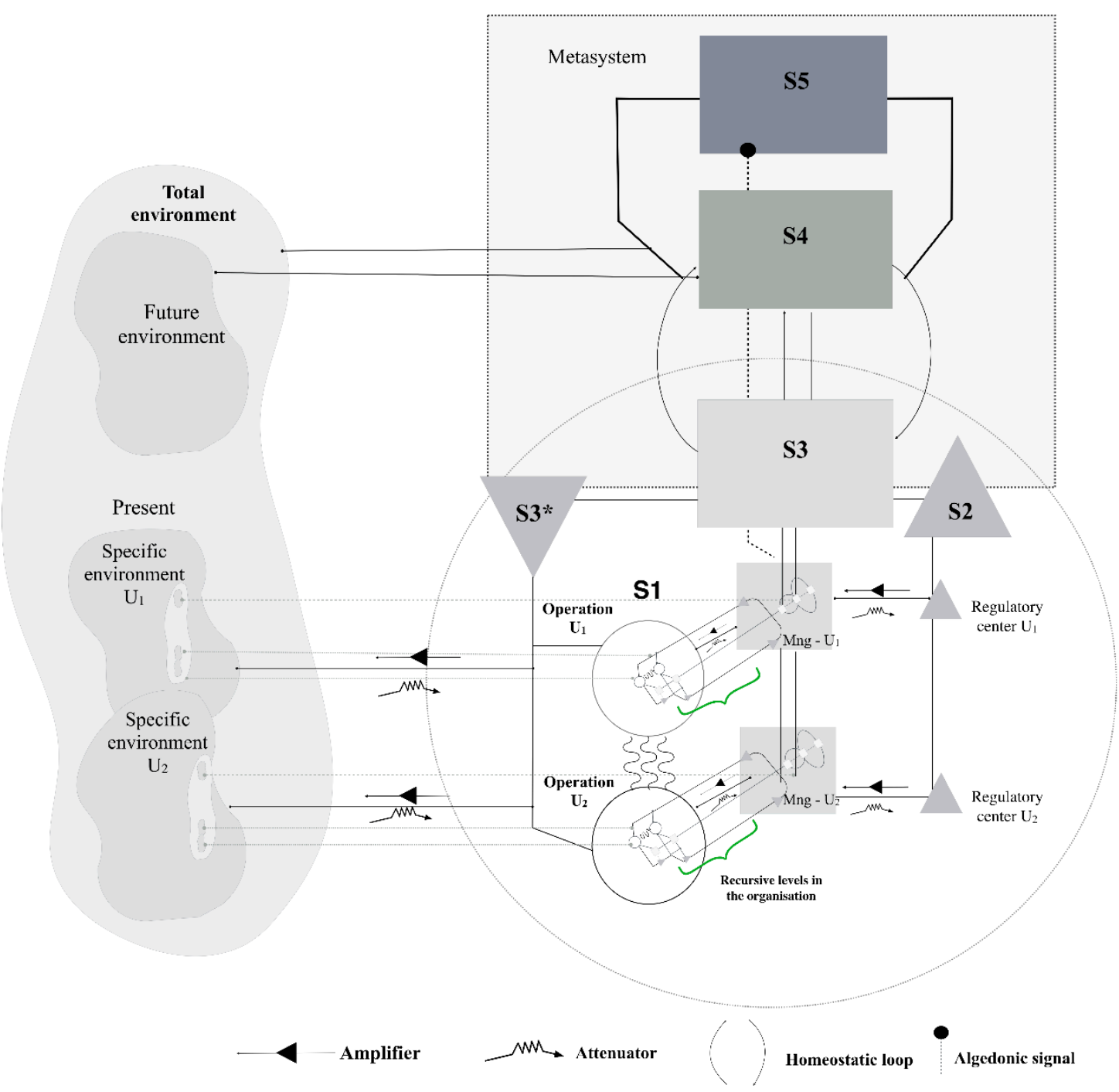

Figure 2. Viable system model (VSM) as a basis for the conceptual model (The S3* is a specialised function of S3. Beer uses the * sign to denote this is a support function). Source: based on Beer [42].

According to Mouhib et al. [45], the VSM is an alternative to solve structural problems in an organisation. It considers three essential elements of the internal and external interactions of a system: environment, management and operations, which are necessary to ensure its viability. Also, by integrating attenuators and amplifiers, it regulates internal and external interactions, absorbing 
from the environment only the variety required by the system and amplifying the variety that is to be delivered. Additionally, the PLS-PM method was used, which is a soft modelling tool that allows researchers to address unstructured problems and treat them as one-dimensional problems. Moreover, it helps validate a conceptual model because: 1 ) it analyses multiple blocks of variables; 2 ) it assumes that a theoretical concept represents each block of variables; 3 ) it assumes the existence of linear relationships between blocks of variables [46]. Therefore, its application sought to verify the significance and congruence of the relationships proposed in the conceptual model.

It is considered pertinent to provide a concrete definition of the VSM components as well as to emphasise that its application was oriented, first, to identify if they existed and functioned in the RAMSAR site under study and, second, they served as a basis for restating and proposing new relationships in the organisational structure. The components of the VSM are:

- S1: It is in charge of producing and delivering to the environment the goods and services generated by the organisation.

- S2: This system is in charge of the harmonic operation of the operating units constituting System 1.

- S3: This is the system in charge of managing the operational units of the organisation. This system deals with the here and now of the organisation.

- S3*: This system is also integrated, which is a support function to S3 and obtains information on the operation of the S1 units, which S3 cannot capture.

- S4: The primary function of this system is to deal with the future and the environment of the organisation.

- S5: This system is the highest authority of the organisation. Balances the present and future of the organisation, taking into account internal and external factors affecting the organisation.

Based on the above, the methodology for this study was as follows:

1. Identify conflicting components through the VSM.

2. Express a conceptual model based on the VSM as an improvement alternative.

3. Propose the hypotheses derived from the conceptual model.

4. Design and apply a questionnaire considering the variables of the conceptual model.

5. Analyse the data to validate the conceptual model.

6. Enrich the design of the VSM with the results obtained.

\section{Viable System Model and Partial Least Squares Path Modeling (PLS-PM) Application to the Problem Situation}

\subsection{Identification of Conflicts through Viable System Model (VSM)}

According to Cardoso Castro [47], the VSM can be applied to any organisation regardless of its size, nature or operating context for diagnosis or to restructure in order to achieve viability. Its functionality has been demonstrated in different sectors [48-57]. It should be added that for the VSM operation, five subsystems interact continuously, seeking to maintain an organisation in equilibrium as well as to ensure its survival through learning and adaptation processes. To achieve this, Beer [42] indicated that subsystems S1, S2, S3, S4, S5 and S3* must be present in any organisation. So, it is possible to diagnose any organisation contrasting its problems with the systems mentioned above. In this sense, Table 1 presents each subsystem and the problems identified in the sites under study. 
Table 1. VSM functions and situation regarding RAMSAR sites.

\begin{tabular}{|c|c|c|}
\hline Function & Problem & Status \\
\hline S1 & $\begin{array}{l}\text { Essential operations are identified: however, they do not all respond to } \\
\text { a specific environment or relate to a management mechanism }\end{array}$ & Non-functional \\
\hline S2 & $\begin{array}{l}\text { The existing technical and public policy framework does not strengthen } \\
\text { or regulate the relationship of operations as well as the generation of } \\
\text { information }\end{array}$ & Non-functional \\
\hline S3: & \multirow{2}{*}{$\begin{array}{l}\text { No functions or mechanisms are identified that facilitate the work of the } \\
\text { operating units or that seek their autonomy to contribute to balance and } \\
\text { sustainable performance; this implies that the current way of operating } \\
\text { performs actions contrary to the purpose of the whole }\end{array}$} & \multirow{2}{*}{ Non-existent } \\
\hline $\begin{array}{l}\text { S3* } \\
\text { (Beer uses the }{ }^{*} \text { to denote } \\
\text { the support function) }\end{array}$ & & \\
\hline S4: & $\begin{array}{l}\text { Little capacity to adapt to changes in the environment due to the lack of } \\
\text { mechanisms for importing information from the environment and } \\
\text { processing it to adjust courses of action }\end{array}$ & Non-existent \\
\hline S5: & $\begin{array}{l}\text { It does not have communication with } \mathrm{S} 4 \text {, and this does not allow it to } \\
\text { manage or generate policies applicable to the whole system in order to } \\
\text { orient itself towards sustainable performance. Its configuration does } \\
\text { not consider top-down intervention to adjust internal conflicts that } \\
\text { affect the response to environmental challenges }\end{array}$ & Non-functional \\
\hline
\end{tabular}

Source: self-elaboration based on Beer [42].

\subsection{Conceptual Model}

Based on the literature review, the problems expressed in the previous section and the contribution of Panagiotakopoulos et al. [52] a conceptual model is proposed, in PLS-PM terms, that considers the sustainable performance (see Figure 3). This construct, whose underlying variables are based on the definition of the VSM components, introduces the following general hypothesis: "Sustainable performance on RAMSAR sites depends on the coherent interaction of variables such as Environment, Primary activities, Coordination, Operations Management, Audit, Intelligence and Policy".

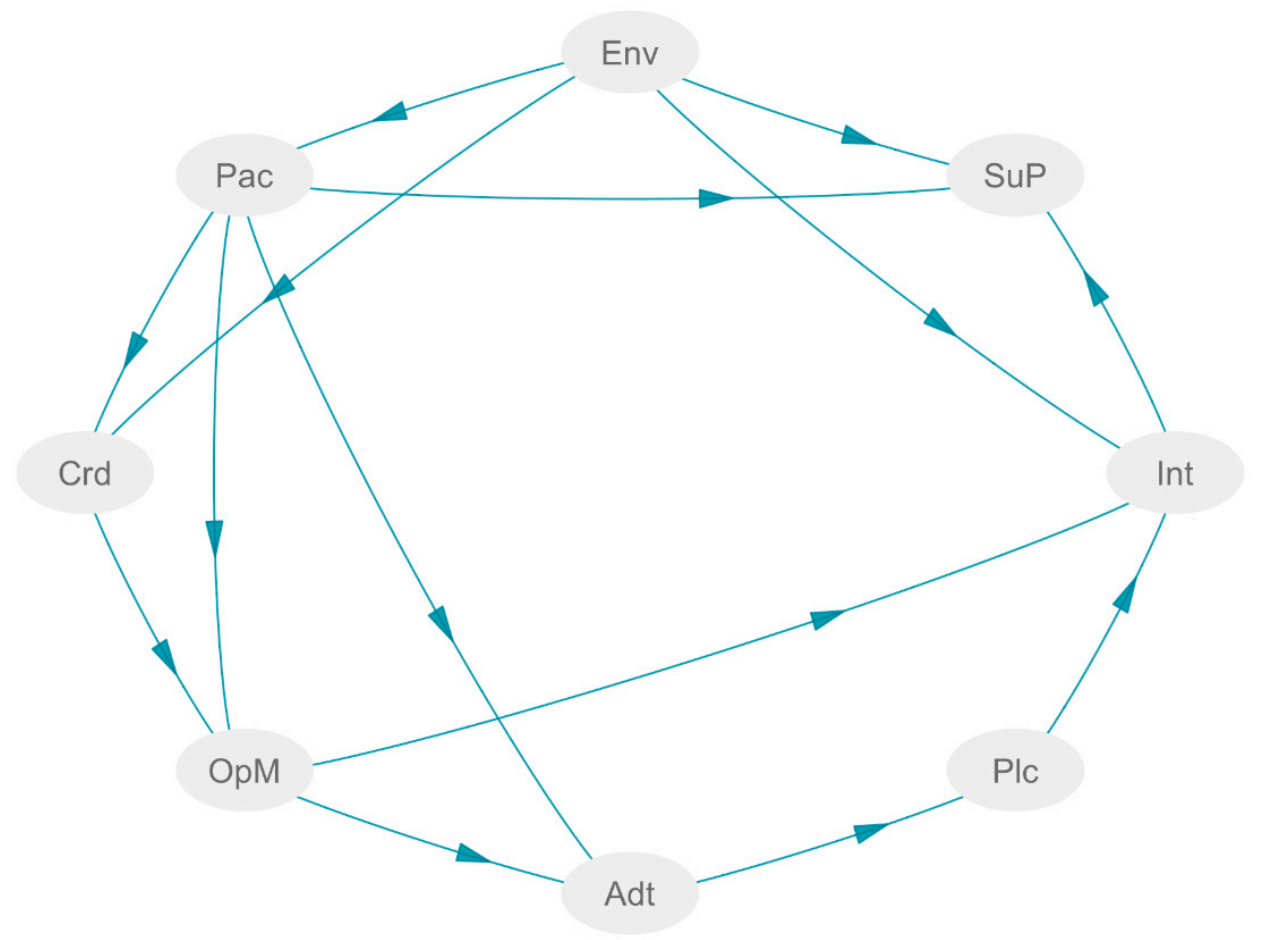

Figure 3. Conceptual model.

Given the preceding, the hypotheses which conform to the proposed construct are as follows: 
$\mathbf{H}_{\mathbf{1}}$. Environment is positively related to Primary activities.

$\mathbf{H}_{2}$. Environment has a positive effect on Coordination.

$\mathbf{H}_{3}$. Environment positively influences to Intelligence.

$\mathbf{H}_{4}$. Environment is positively related to Sustainable operations.

$\mathbf{H}_{5}$. Primary activities are significantly related to Coordination.

$\mathbf{H}_{6}$. Primary activities have a positive effect on Operations Management.

$\mathbf{H}_{7}$. Primary activities are significantly related to Audit.

$\mathbf{H}_{8}$. Primary activities are significantly related Sustainable operations.

$\mathbf{H}_{\mathbf{9}}$. Coordination is positively related to Operation Management.

$\mathbf{H}_{10}$. Operations Management have positive effect on Audit.

$\mathbf{H}_{11}$. Operations Management is positively related to Intelligence.

$\mathbf{H}_{\mathbf{1 2}}$. Audit positively influences on Policy.

$\mathbf{H}_{13}$. Policy has a positive effect on Intelligence.

$\mathbf{H}_{14}$. Intelligence is positively and significantly related to Sustainable operations.

\subsection{Information Collection}

The questionnaire was based on previous research by Valdez-Juárez et al. [35], Garrity [38] and Barba-Sánchez and Atienza-Sahuquillo [58]. The measurement scale was compiled using a Likert scale of up to 5 points from 1 (completely disagree) to 5 (completely agree). In this regard, Table 2 describes variables and items used and Table 3 shows statistical descriptions of the application of the instrument.

Table 2. Variables and items description.

\begin{tabular}{|c|c|c|c|}
\hline Variable & Definition & Item & Id \\
\hline \multirow{2}{*}{$\begin{array}{l}\text { Environment } \\
\quad(\text { Env })\end{array}$} & \multirow{2}{*}{$\begin{array}{l}\text { The context in which an } \\
\text { organisation operates. It integrates } \\
\text { factors that restrict its actions and } \\
\text { capacity for adaptability }[42,58]\end{array}$} & $\begin{array}{l}\text { Mechanisms for capturing information from the } \\
\text { environment are well established and distribute it } \\
\text { appropriately }\end{array}$ & Env $_{1}$ \\
\hline & & $\begin{array}{l}\text { The suppliers, customers and everything else in the } \\
\text { local environments are continuously mapped }\end{array}$ & $\mathrm{Env}_{2}$ \\
\hline \multirow{3}{*}{$\begin{array}{l}\text { Primary activities } \\
\text { (Pac) }\end{array}$} & \multirow{3}{*}{$\begin{array}{l}\text { Activities that respond to a } \\
\text { particular environment, the } \\
\text { processing of inputs is vital to meet } \\
\text { the organisational objective [59] }\end{array}$} & $\begin{array}{l}\text { In the organisation each operational unit (OU) } \\
\text { attends to a specific responsibility or service of the } \\
\text { organisation without overloading itself with tasks }\end{array}$ & $\mathrm{Pac}_{1}$ \\
\hline & & $\begin{array}{l}\text { In the organisation, each OU is competent, capable, } \\
\text { autonomous and flexible to serve their market areas } \\
\text { comprehensively (in conjunction with third parties, } \\
\text { when necessary) }\end{array}$ & $\mathrm{Pac}_{2}$ \\
\hline & & Each OU has clear and measurable objectives & $\mathrm{Pac}_{3}$ \\
\hline \multirow[t]{2}{*}{$\begin{array}{l}\text { Coordination } \\
\quad(\mathrm{Crd})\end{array}$} & \multirow[t]{2}{*}{$\begin{array}{l}\text { Actions that seek cohesion and } \\
\text { regulation of primary activities } \\
{[35,59]}\end{array}$} & $\begin{array}{l}\text { Regarding internal and external activities, frictional } \\
\text { losses and inefficiencies between OUs is avoided } \\
\text { with effective coordination functions (for mutual } \\
\text { approval, determining responsibilities, limits, } \\
\text { assignment, regulation, codes of conduct, criteria for } \\
\text { decision making) }\end{array}$ & $\mathrm{Crd}_{1}$ \\
\hline & & $\begin{array}{l}\text { The standard parameters of the organisation (current } \\
\text { and objective control parameters) are continuously } \\
\text { monitored, and the deviations are adjusted }\end{array}$ & $\mathrm{Crd}_{2}$ \\
\hline
\end{tabular}


Table 2. Cont

\begin{tabular}{|c|c|c|c|}
\hline Variable & Definition & Item & Id \\
\hline \multirow{2}{*}{$\begin{array}{l}\text { Operational } \\
\text { Management } \\
(\mathrm{OpM})\end{array}$} & \multirow{2}{*}{$\begin{array}{l}\text { Exert control and management to } \\
\text { maintain the daily activities taking } \\
\text { care of the "here and now" of the } \\
\text { organisation. It frequently assesses } \\
\text { the effectiveness of the Pac in } \\
\text { strengthening the essence of the } \\
\text { organisation [59] }\end{array}$} & $\begin{array}{l}\text { The OpM monitors and optimizes the organisation } \\
\text { as a whole using control measures, resource } \\
\text { allocation and parameter changes concerning the } \\
\text { overall operation }\end{array}$ & $\mathrm{OpM}_{1}$ \\
\hline & & $\begin{array}{l}\text { Decision-making of OpM is based on } \\
\text { internal/organisational and market and the } \\
\text { environment information, and If necessary, the OpM } \\
\text { triggers regulatory measures or adjustments }\end{array}$ & $\mathrm{OpM}_{2}$ \\
\hline \multirow[t]{2}{*}{$\begin{array}{l}\text { Audit } \\
\text { (Adt) }\end{array}$} & \multirow{2}{*}{$\begin{array}{l}\text { In a complementary sense, the } \\
\text { monitoring and collection of } \\
\text { information that was not captured } \\
\text { by OpM }[42,58]\end{array}$} & $\begin{array}{l}\text { Independent information from the management is } \\
\text { repeatedly collected regarding the state of the } \\
\text { organisation through surprise audits, surveys or } \\
\text { conversations }\end{array}$ & $\mathrm{Adt}_{1}$ \\
\hline & & $\begin{array}{l}\text { Key performance indicators (KPIs) are designed to } \\
\text { measure performance in real terms }\end{array}$ & $\mathrm{Adt}_{2}$ \\
\hline \multirow{3}{*}{$\begin{array}{l}\text { Intelligence } \\
\quad \text { (Int) }\end{array}$} & \multirow{3}{*}{$\begin{array}{l}\text { Continuous monitoring of the } \\
\text { organisation's context to generate } \\
\text { forecasts and relevant information } \\
\text { to support the organisation's } \\
\text { adaptation and sustainable } \\
\text { operations [ } 42 \text { ] }\end{array}$} & $\begin{array}{l}\text { Analysis of the environment and planning is made to } \\
\text { improve adaptive capabilities in the organisation }\end{array}$ & $\operatorname{Int}_{1}$ \\
\hline & & $\begin{array}{l}\text { The intelligence function influences the organisation } \\
\text { and is considered an important part of the course of } \\
\text { the organisation }\end{array}$ & $\mathrm{Int}_{2}$ \\
\hline & & $\begin{array}{l}\text { New plans and courses of action are based on } \\
\text { environmental analysis and translated for the entire } \\
\text { organisation to understand }\end{array}$ & $\mathrm{Int}_{3}$ \\
\hline \multirow{2}{*}{$\begin{array}{l}\text { Policy } \\
(\mathrm{Plc})\end{array}$} & \multirow{2}{*}{$\begin{array}{l}\text { Definition of purpose and policy for } \\
\text { the entire organisation. It proposes } \\
\text { courses of action based on Int [59] }\end{array}$} & $\begin{array}{l}\text { The plans and decision making are based on } \\
\text { information from Int, together with data on the } \\
\text { organisation and corporate policy OpM, } \\
\text { opportunities and risks are recognised }\end{array}$ & $\mathrm{Pl}_{1}$ \\
\hline & & $\begin{array}{l}\text { Plc ensures the linking guidelines and general } \\
\text { objective definitions, informing the whole } \\
\text { organisation }\end{array}$ & $\mathrm{Pl}_{2}$ \\
\hline \multirow{2}{*}{$\begin{array}{l}\text { Sustainable } \\
\text { Performace } \\
\quad(\mathrm{SuP})\end{array}$} & \multirow{2}{*}{$\begin{array}{l}\text { Actions carried out by any } \\
\text { organisation to meet its objectives } \\
\text { without neglecting the ability to } \\
\text { adapt or balance with its } \\
\text { environment [59] }\end{array}$} & $\begin{array}{l}\text { Global units (company, division, branch) are able to } \\
\text { operate and fulfil their mission independently and } \\
\text { respond quickly to changes in the environment by } \\
\text { considering real-time information }\end{array}$ & $\mathrm{SuP}_{1}$ \\
\hline & & $\begin{array}{l}\text { Operations at each organisational level are } \\
\text { comprehensive and inclusive, fostering sustainability }\end{array}$ & $\mathrm{SuP}_{2}$ \\
\hline
\end{tabular}

Source: based on Valdez-Juárez et al. [35] and Barba-Sánchez and Atienza-Sahuquillo [58].

The questionnaire was applied to 1300 people, 1000 questionnaires were $100 \%$ filled, and the rest discarded because they were incomplete. Therefore, the sample in this study consists of 1000 observations composed of 50 managers, 290 employees, 50 suppliers, 60 associations of protected natural areas, 50 government officials and 500 visitors, seeking to comply with a condition of systemic thinking, that is, to obtain the vision of the different agents involved in a problematic situation $[50,60]$. Regarding the size and composition of the sample, it is considered pertinent to mention that no rigid guidelines are identified for the minimum necessary because different factors depend on access to data, organisations or the context of the problem itself [61]. However, Hair et al. [62] and Kock [63] recommend that the minimum sample should be between 140 and 200 observations to obtain meaningful using PLS-PM.

The data were processed in Rstudio using the following steps [61]:

1. Reviewing the unidimensionality of the latent variables (LV) in the measurement model through Cronbach's alpha coefficients and Dillon-Goldstein's rho, which must exceed 0.7. Complementarily, the first eigenvalue must exceed 1 , and the second must be less than 1 .

2. The factorial loading for each indicator must be greater than 0.7 , for it to explain at least $50 \%$ of the variability of the latent variable.

3. Verifying that all indicators are a good proxy of its LV by estimating the cross-loadings. That is, the higher factorial loading corresponds to the indicator to which it belongs. 
4. Analysing the structural model, checking the determination coefficients $\mathrm{R}^{2}$, reporting the amount of variance in the dependent variables explained by their independent variables $\left(R^{2}<0.2\right.$ low, $0.2<R^{2}<0.5$ moderate, $R^{2}>0.5$ high). Redundancy is also analysed because it indicates the predictive capability of the dependent variables by the independent variables; i.e., the higher the value is, the greater the capability.

5. Running a bootstrapping analysis to validate the meaningful relationships. This produces a confidence interval for each path coefficient related to the model. If this value is not 0 , it can be said that the hypothesis is significant with a $95 \%$ reliability.

Table 3. Variables and items for the conceptual model with corresponding mean $(\mu)$ and standard deviation $(\sigma)$ values.

\begin{tabular}{|c|c|c|c|}
\hline Variable & Id & $\mu$ & $\sigma$ \\
\hline \multirow{2}{*}{ Environment } & Env $_{1}$ & 3.57 & 1.15 \\
\hline & $\mathrm{Env}_{2}$ & 3.72 & 1.01 \\
\hline \multirow{2}{*}{ Coordination } & $\mathrm{Crd}_{1}$ & 3.82 & 1.13 \\
\hline & $\mathrm{Crd}_{2}$ & 3.33 & 1.21 \\
\hline \multirow{3}{*}{ Primary activities } & $\mathrm{Pac}_{1}$ & 3.63 & 1.18 \\
\hline & $\mathrm{Pac}_{2}$ & 3.67 & 1.22 \\
\hline & $\mathrm{Pac}_{3}$ & 3.57 & 1.29 \\
\hline \multirow{2}{*}{ Audit } & $\mathrm{Adt}_{1}$ & 3.93 & 1.04 \\
\hline & $\mathrm{Adt}_{2}$ & 2.89 & 1.42 \\
\hline \multirow{2}{*}{ Policy } & $\mathrm{Plc}_{1}$ & 3.37 & 1.29 \\
\hline & $\mathrm{Pl}_{2}$ & 3.33 & 1.21 \\
\hline \multirow{3}{*}{ Operative management } & $\mathrm{OpM}_{1}$ & 3.63 & 1.18 \\
\hline & $\mathrm{OpM}_{2}$ & 4.1 & 1.03 \\
\hline & $\mathrm{OpM}_{3}$ & 4.1 & 1.03 \\
\hline \multirow{2}{*}{ Intelligence } & Int $_{1}$ & 3.88 & 1.09 \\
\hline & $\mathrm{Int}_{2}$ & 3.82 & 1.13 \\
\hline \multirow{2}{*}{ Sustainable Performance } & $\mathrm{SuP}_{1}$ & 3.82 & 1.13 \\
\hline & $\mathrm{SuP}_{2}$ & 3.61 & 1.14 \\
\hline
\end{tabular}

\section{Conceptual Model Assessment through PLS-PM}

\subsection{Analysis of the measurement model}

Table 4 reports on the unidimensionality of the construct variables using Dillon-Goldstein's rho and eigenvalues. According to Marcoulides et al. [64], Dillon-Goldstein's rho is considered a better indicator of internal consistency, and in this study, all rho values exceed 0.7 establishing the validity of the measurement scale. Complementarily, all variables report the first eigenvalue above than 1 and the second eigenvalue less than 1 . Together, these statistics corroborate the unidimensionality of the items by providing vital information to measure the LV to which they correspond. 
Table 4. DG rho $(\rho)$, first and second eigenvalues to measure internal consistency of each latent variable.

\begin{tabular}{cccc}
\hline & $\boldsymbol{\rho}$ & eig.1 & eig.2 \\
\hline Environment (Env) & 0.72 & 1.12 & 0.88 \\
Primary activities (Pac) & 0.82 & 1.78 & 0.76 \\
Coordination (Crd) & 0.81 & 1.36 & 0.64 \\
Operational Management (OpM) & 0.87 & 2.12 & 0.88 \\
Audit (Adt) & 0.78 & 1.24 & 0.76 \\
Policy (Plc) & 0.81 & 1.36 & 0.64 \\
Intelligence (Int) & 0.81 & 1.35 & 0.65 \\
Sustainable Performance (SuP) & 0.85 & 1.48 & 0.52 \\
\hline
\end{tabular}

Table 5 provides item information in terms of discriminant validity; it also shows that factorial loadings $[\lambda]$ do not overlap with cross factorial load ranges [C- $\lambda]$. This makes it possible to rule out the existence of indicators not being a proper proxy of its $L V$, since $\lambda>C-\lambda$, in line with the recommendations of some authors [65]. The proposed model complies with the discriminatory validity because each indicator reports more $\lambda$ towards the LV to which it belongs than to others [66]. Additionally, this validity exists between two variables if $\mathrm{R}^{2}<\mathrm{AVE}$, i.e., that the shared variance of an $L V$ is less than its extracted variance [67]. Compliance with this condition can be verified by revising the corresponding columns of Table 6. Regarding convergent validity, this is assumed if the range of the factorial loadings $[\lambda]$ is narrow and the value of the lower limit of the loading for each LV is more significant [62].

Table 5. Factor loadings $(\lambda)$, cross-loadings $(C-\lambda)$ and AVE values for each indicator.

\begin{tabular}{ccc}
\hline Indicator & {$[\lambda]$} & {$[\mathrm{C}-\lambda]$} \\
\hline Env $_{1}$ & 0.71 & $0.21-0.26$ \\
Env $_{2}$ & 0.78 & $0.17-0.29$ \\
$\mathrm{Pac}_{1}$ & 0.77 & $0.29-0.75$ \\
$\mathrm{Pac}_{2}$ & 0.76 & $0.26-0.55$ \\
$\mathrm{Pac}_{3}$ & 0.75 & $0.23-0.46$ \\
$\mathrm{Crd}_{1}$ & 0.87 & $0.27-0.84$ \\
$\mathrm{Crd}$ & 0.81 & $0.32-0.79$ \\
$\mathrm{OpM}_{1}$ & 0.77 & $0.29-0.75$ \\
$\mathrm{OpM}_{2}$ & 0.81 & $0.24-0.50$ \\
$\mathrm{OpM}_{3}$ & 0.83 & $0.24-0.51$ \\
$\mathrm{Adt}_{1}$ & 0.72 & $0.20-0.38$ \\
$\mathrm{Adt}_{2}$ & 0.84 & $0.23-0.51$ \\
$\mathrm{Pl}_{1}$ & 0.83 & $0.28-0.58$ \\
$\mathrm{Plc}_{2}$ & 0.83 & $0.32-0.80$ \\
$\mathrm{Int}_{1}$ & 0.74 & $0.28-0.48$ \\
$\mathrm{Int}_{2}$ & 0.89 & $0.27-0.85$ \\
$\mathrm{SuP}_{1}$ & 0.91 & $0.27-0.88$ \\
$\mathrm{SuP}_{2}$ & 0.80 & $0.25-0.57$ \\
\hline
\end{tabular}

Table 6. Type of variable, $\mathrm{R}^{2}$, redundancy and Average Variance Extracted values by latent variable.

\begin{tabular}{clccc}
\hline Variable & Type & $\boldsymbol{R}^{\mathbf{2}}$ & Redundancy & AVE \\
\hline Env & Exogenous & 0.00 & 0.00 & 0.56 \\
Pac & Endogenous & 0.12 & 0.07 & 0.58 \\
Crd & Endogenous & 0.38 & 0.26 & 0.68 \\
OpM & Endogenous & 0.63 & 0.41 & 0.65 \\
Adt & Endogenous & 0.31 & 0.19 & 0.62 \\
Plc & Endogenous & 0.32 & 0.21 & 0.68 \\
Int & Endogenous & 0.34 & 0.23 & 0.67 \\
SuP & Endogenous & 0.69 & 0.50 & 0.73 \\
\hline
\end{tabular}


Figure 4 presents $\lambda$ for each of the indicators in their respective blocks reporting on the composition and relative importance of each component in its corresponding LV [68]. In this model, all items obtained a $\lambda$ greater than 0.7 , surpassing the minimum threshold to establish a communality equivalent to 0.5 , and thus confirming that each indicator explains at least $50 \%$ variance of each LV $[61,65]$.

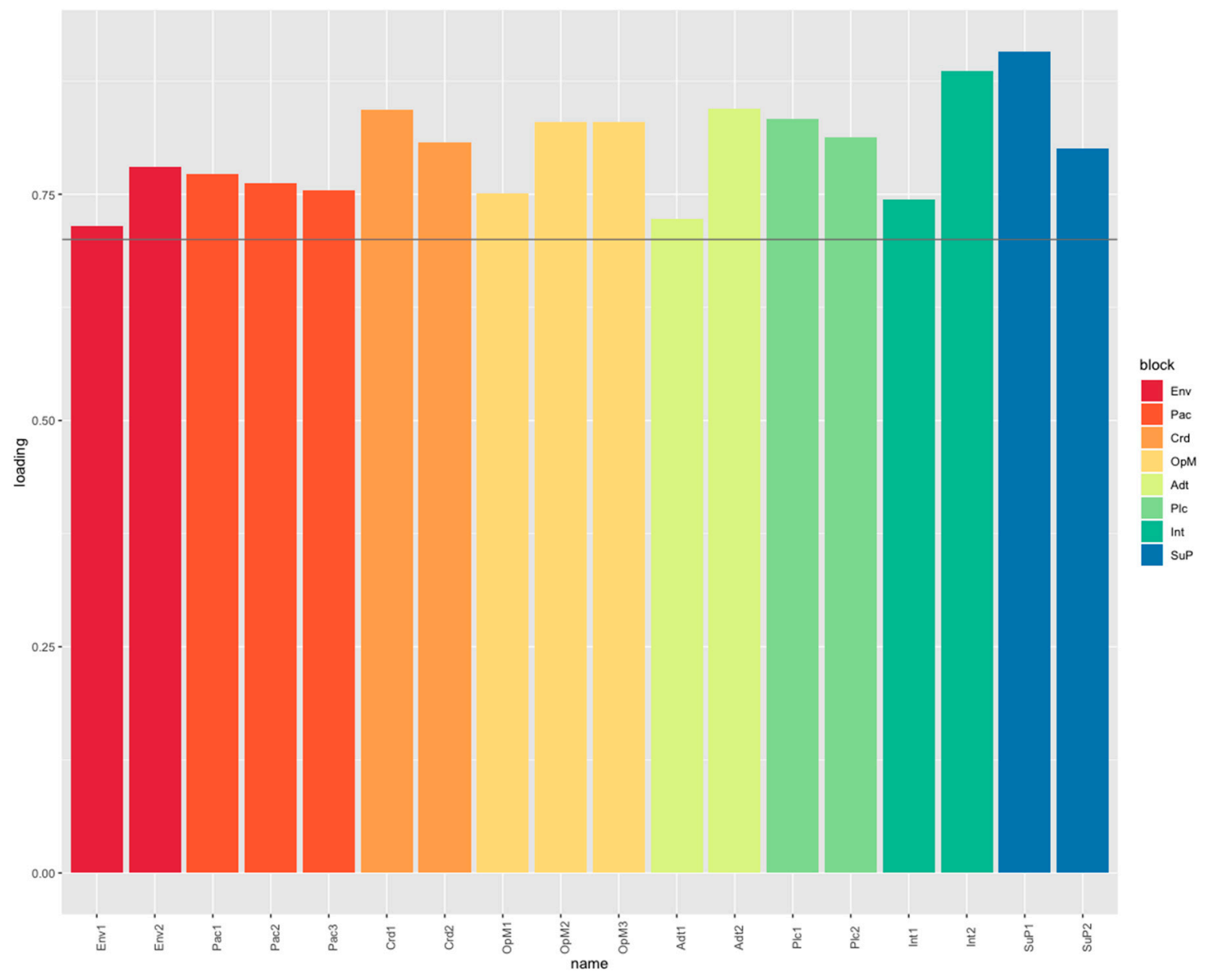

Figure 4. Bar chart loadings for each indicator.

\subsection{Analysis of the structural model}

Figure 5 depicts the path coefficients of the proposed relationships in the conceptual model and Table 6 the results of the bootstrapping analysis. Based on these, it stands out that elements such as $\mathrm{PaC}$, Env, OpM or Plc, do not constitute components that by themselves significantly influence SuP. However, interaction with the other variables amplifies their effect on Sustainable Performance. It is also possible to infer that the configuration of the relations in the model allows achieving sustainable operations, but this demands high monitoring of the environment in order to filter adequate information for this purpose. Besides, critical components such as the influence of the environment on primary activities and coordination mechanisms must be addressed. Likewise, the actors responsible for management and change must be congruent with Primary activities, Coordination, Operational Management and Audit relationships, since their interaction is critical for the reduction of conflicts and to propitiate synergies towards a sustainable organisational behaviour. 


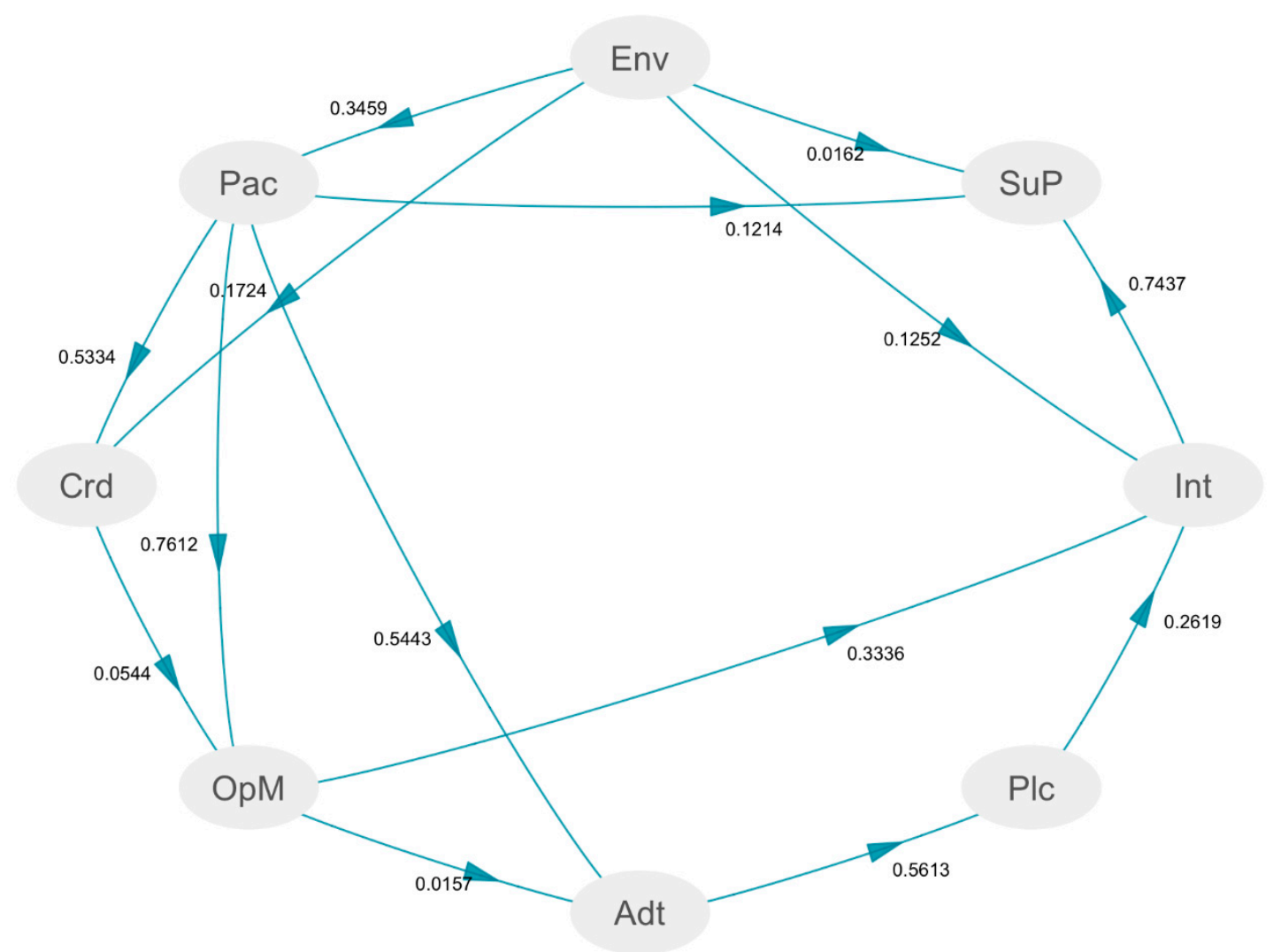

Figure 5. Paths coefficients for the proposed relations in the model.

Considering the information in Table 6 , the determination coefficients $\left(R^{2}\right)$ indicate to what extent the level of variance for each endogenous variable is explained by exogenous variables, providing an overview of the quality of the model. In this respect, and according to the ranges established by Hair et al. [62], the Sustainable Performance and Operational Management variables have a substantial $R^{2}$ while the rest of the variables explain a moderate level of variance. Table 6 also reports on the redundancy of the variables and the calculations for most endogenous variables is greater than 0 , which supports the predictive relevance of the construct. As for the value of goodness-of-fit $(\mathrm{GoF})$, a value of 0.52 was obtained, meaning an adequate predictive or explanatory capability [46].

In a confirmatory way, the bootstrapping analysis allowed us to validate the significance of the relationships of the model (Table 7). This analysis, together with an associated confidence interval, indicates the degree of stability or how acceptable the sample statistic is as an estimate of the population parameter [61]. Therefore, if the confidence intervals (perc.025 to perc.975) do not contain a value of 0 , it is estimated that such a significant relationship is $95 \%$ reliable. Derived from this, 12 of the 14 expressed hypotheses are supported. This means that the probability of achieving a Sustainable Performance $(\mathrm{SuP})$ is high if the RAMSAR sites under study adopt an organisational form based on the structural arrangement described by the VSM. 
Table 7. Bootstrapping analysis by latent variables, ${ }^{* * *}$ significance with a confidence interval at 95\% level.

\begin{tabular}{ccccccc}
\hline & Original & Mean.Boot & Std.Error & perc.025 & perc.975 & Signf. \\
\hline Env -> Pac & 0.3459 & 0.3477 & 0.0271 & 0.2952 & 0.3980 & $* * *$ \\
Env -> Crd & 0.1724 & 0.1725 & 0.0278 & 0.1168 & 0.2251 & $* * *$ \\
Env -> Int & 0.1252 & 0.1260 & 0.0282 & 0.0710 & 0.1845 & $* * *$ \\
Env -> SuP & 0.0162 & 0.0169 & 0.0193 & -0.0232 & 0.0544 & - \\
Pac -> Crd & 0.5334 & 0.5332 & 0.0228 & 0.4862 & 0.5761 & $* * *$ \\
Pac -> OpM & 0.7612 & 0.7616 & 0.0201 & 0.7204 & 0.8000 & $* * *$ \\
Pac -> Adt & 0.5443 & 0.5462 & 0.0418 & 0.4647 & 0.6295 & $* * *$ \\
Pac -> SuP & 0.1214 & 0.1192 & 0.0236 & 0.0748 & 0.1644 & $* * *$ \\
Crd -> OpM & 0.0544 & 0.0547 & 0.0225 & 0.0106 & 0.1011 & $* * *$ \\
OpM -> Adt & 0.0157 & 0.0140 & 0.0438 & -0.0671 & 0.0980 & - \\
OpM -> Int & 0.3336 & 0.3342 & 0.0326 & 0.2714 & 0.3985 & $* * *$ \\
Adt -> Plc & 0.5613 & 0.5618 & 0.0214 & 0.5205 & 0.6025 & $* * *$ \\
Plc -> Int & 0.2619 & 0.2615 & 0.0320 & 0.1999 & 0.3266 & $* * *$ \\
Int -> SuP & 0.7437 & 0.7450 & 0.0162 & 0.7130 & 0.7765 & $* * *$ \\
\hline
\end{tabular}

Complementarily, and to support the bootstrapping analysis, Table 8 presents the estimates of the $p$-values, being mostly lower than 0.001 , which corroborates the significance of the relationships proposed for this study.

Table 8. Values of the T test and their significance: ${ }^{* * *}$ with 0.001 and * with 0.05 of confidence level.

\begin{tabular}{cccccc}
\hline & Estimate & Std.Error & t value & $\operatorname{Pr}(>|t|)$ & Signf. \\
\hline Env -> Pac & 0.3459 & 0.0297 & 11.6467 & 0.0000 & $* * *$ \\
Env -> Crd & 0.1724 & 0.0266 & 6.4753 & 0.0000 & $* * *$ \\
Env -> Int & 0.1252 & 0.0282 & 4.4461 & 0.0000 & $* * *$ \\
Env -> SuP & 0.0162 & 0.0191 & 0.8454 & 0.3981 & - \\
Pac -> Crd & 0.5334 & 0.0266 & 20.0320 & 0.0000 & $* * *$ \\
Pac -> OpM & 0.7612 & 0.0239 & 31.8815 & 0.0000 & $* * *$ \\
Pac -> Adt & 0.5443 & 0.0432 & 12.5923 & 0.0000 & $* * *$ \\
Pac -> SuP & 0.1214 & 0.0228 & 5.3279 & 0.0000 & $* * *$ \\
Crd - > OpM & 0.0544 & 0.0239 & 2.2787 & 0.0229 & $*$ \\
OpM -> Adt & 0.0157 & 0.0432 & 0.3633 & 0.7165 & - \\
OpM -> Int & 0.3336 & 0.0307 & 10.8656 & 0.0000 & $* * *$ \\
Adt -> Plc & 0.5613 & 0.0262 & 21.4238 & 0.0000 & $* * *$ \\
Plc -> Int & 0.2619 & 0.0311 & 8.4323 & 0.0000 & $* * *$ \\
Int -> SuP & 0.7437 & 0.0227 & 32.8153 & 0.0000 & $* * *$ \\
\hline
\end{tabular}

\section{Structuring Sustainable Performance through the VSM}

The PLS-PM results have structural implications for the RAMSAR sites. Considering the path coefficients, one of the challenges is to harmonise the interactions between primary operations with the elements of coordination and control without neglecting the information provided by Int to improve the courses of action and to operate sustainably. Based on the above, it is considered that the VSM can be used as an alternative to translate the information obtained with the PLS-PM and generate organisational changes that lead to a state of viability $[47,51,69]$.

Before proposing the structure for sustainable performance in RAMSAR sites, the recursion level at which VSM is applied is indicated. In this regard, Figure 6 shows five levels of recursion where the system is nested in focus $\left(\mathrm{R}_{0}\right)$ and in which it is intended to rethink the current relationships to lead them to sustainability. 


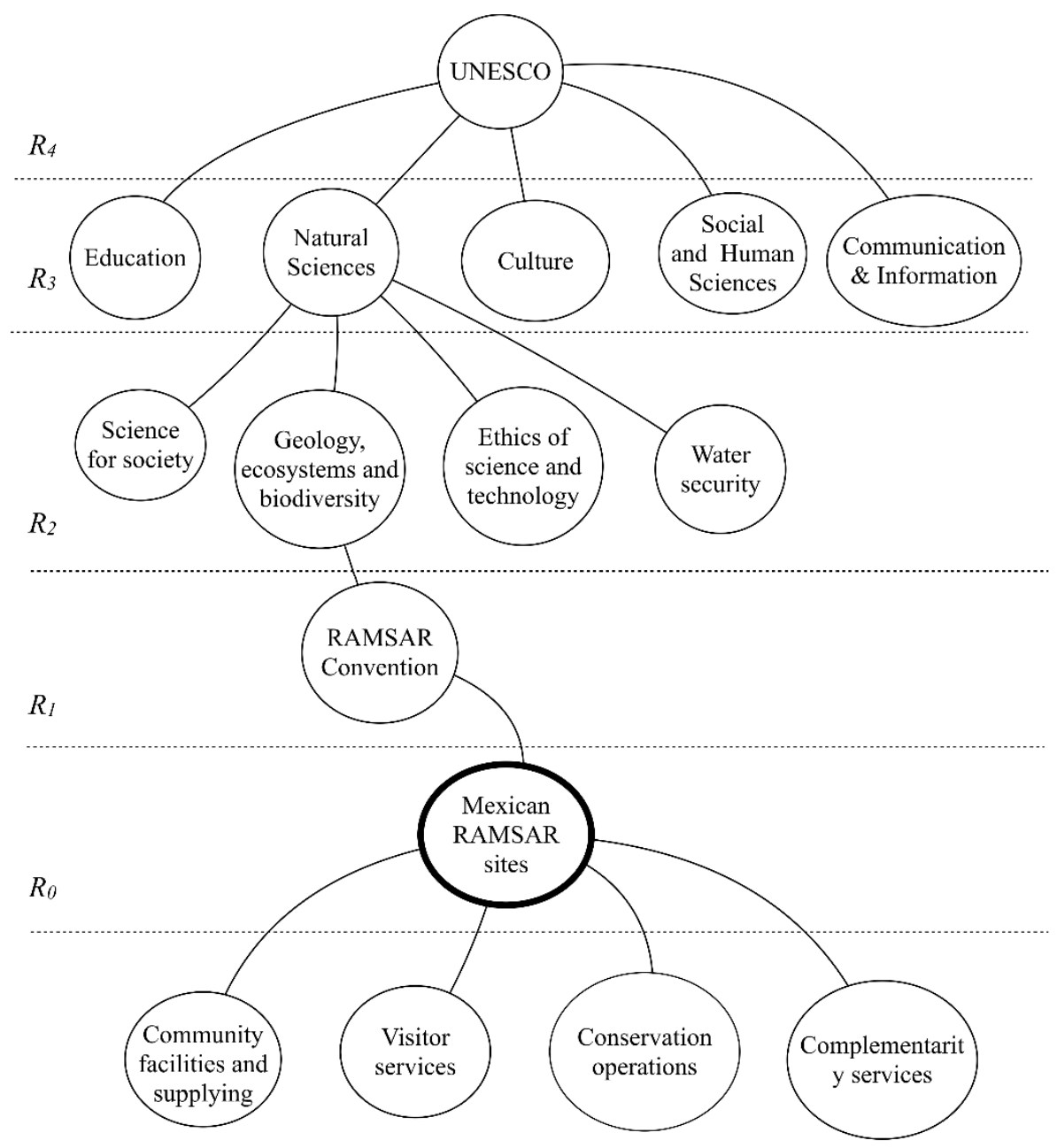

Figure 6. Unfolding complexity of RAMSAR sites. Source: based on Espejo [70].

Considering what has been expressed up to this point and referring back to the problems stated in Section 4.1, the design of the VSM is presented as an alternative to orient the interactions in the sites under study towards sustainable performance (see Figure 7):

The VSM design for RAMSAR sites shown in Figure 7 should be understood in terms of their systems, which are described below:

S1: integrated by four subsystems that cover the essential functions of S1 which are: U1) Community facilities and supplying, U2) Visitors services, U3) Conservation operations and U4) Complementary services. These should work synergistically as a network to provide the services offered by RAMSAR sites that integrate economic activities, without circumventing their operations to the community, environmental conservation, complimentary services for visitors, providing education on the conservation of the sites and generating income for the inhabitants and maintenance activities. The S1 also demands implementation of devices that propitiate an appropriate dialogue with S3 to continuously update its status as well as to share supply needs in equilibrium with the availability and use of the site.

S2: Pursuing sustainability requires linking actions and knowledge that reflect changing environmental conditions as well as understanding the drivers of RAMSAR site change. In that sense, S2 harmonises interactions between S1 utilities to coordinate resource sharing and establish guidelines to ensure sustainable performance.

S3: Monitors and optimises the operational functions of the organisation intending to work harmoniously and achieve the objective set by S5. This requires providing specialised procedures, 
rules and clear guidelines for the operation. Additionally, it is required to integrate suitable indicators, allocation of resources and changes in the parameters (local conditions) concerning the sustainability and functioning in general (effectiveness, productivity, profits, support services, quality) to maximise its effectiveness thought collaboration.

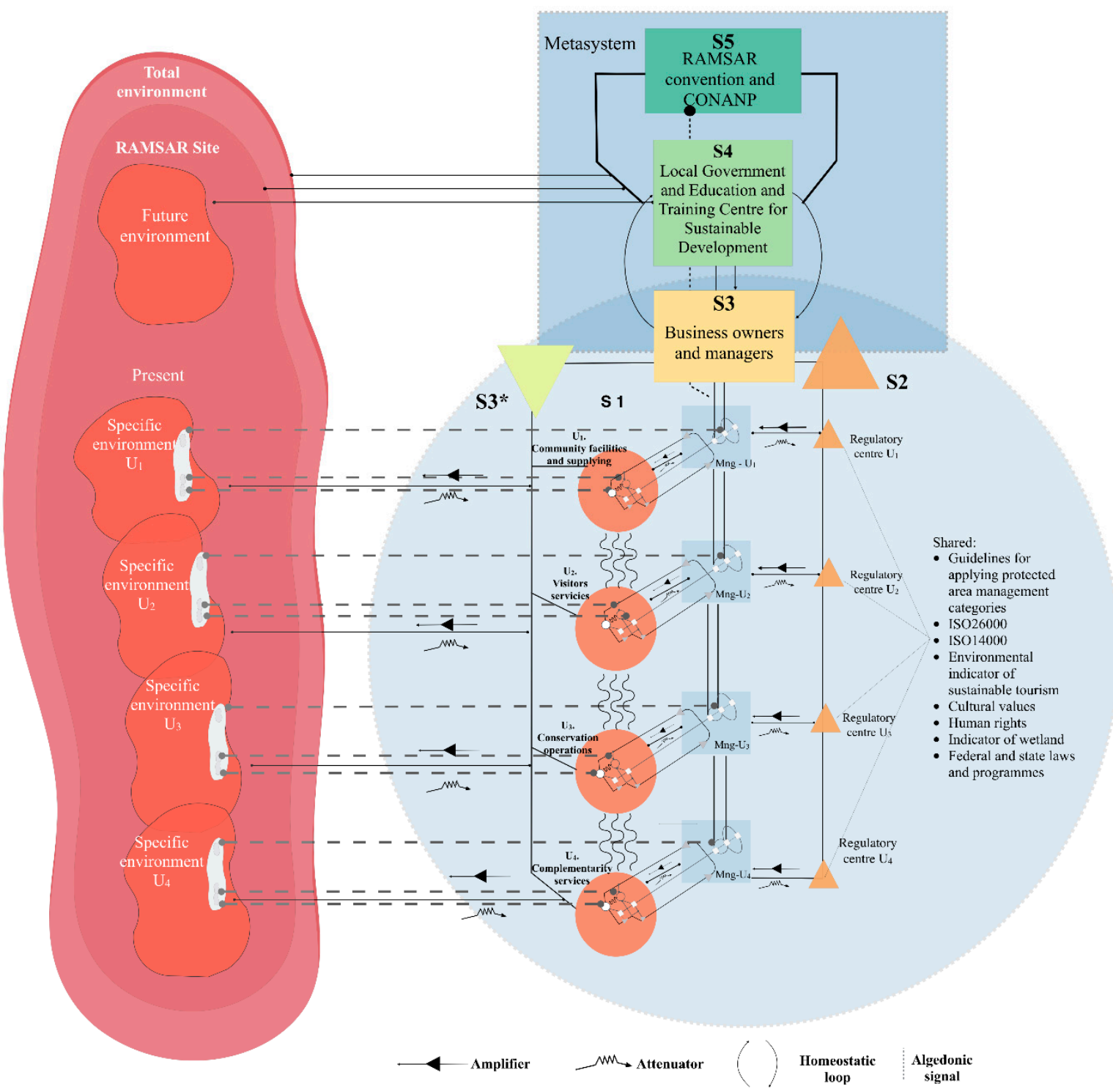

Figure 7. VSM for RAMSAR sites. Source: based on Beer [42]. * Interactions are presented with the connections suggested by the author for promoting sustainable performance. It should be noted that the S1 (corresponding to the Pac variable) responds to a specific environment and suggests its support functions.

The information obtained from S2 and S3*, would allow S3 to continuously negotiate with S1 in terms of sustainable performance and influence operations to modify their courses of action only if the viability of the system is endangered. S3 must share results with S4 to inform the status of the operations developing a framework for the study of the external environment.

S3*: It acts as an audit facility for the validity of information and functionality of operations of S1 to report to S3. Corroborates the key performance indicators (KPIs) in real terms.

S4: Should promote and contribute to the development and maintenance of more harmonious relationships between stakeholders and the organisation always seeking sustainability, i.e., the transduction of exogenous information to understand the complex changes in the environment without 
circumventing sustainable use or natural resources and the social dimension. In S4 the participation of the local government and the training centre for sustainable education is essential. $\mathrm{S} 4$ is also responsible for generating forecasts that enrich decision-making processes and actions in terms of adaptability.

S5: Provides general guidance to the organisation. Its base is established according to the ethos, values and policies established by the RAMSAR Convention and are directed under the National Commission of Protected Areas [15] (CONANP, for its acronym in Spanish) to integrate a sustainable approach. For decision-making, this subsystem is based on information delivered by S4, which considers a balance between the variety of the environment and the information delivered by S3, to set up the dynamics, learning, adaptation and self-organisation of the total system.

\section{Discussion and Conclusion}

As mentioned above, the results obtained have implications for RAMSAR sites. Regarding the Env variable, some common points were found with the work of Banson et al. [15], Van Dyk and Pretorius [16], and Nikolaou et al. [19], as the results indicate that the environment largely dictates the organisation of operational units to support the global strategy. In contrast to the aforementioned contributions, this study considers it necessary to delimit and articulate operational units using the VSM criteria to provide a distinctive and flexible structure to RAMSAR sites to comply with sustainable performance. This requires strengthening factors such as the education and training of operators as well as adopting mechanisms that foster consensus and allow quick decisions with government bodies.

Regarding the Pac variable, it is possible to indicate that the organisational and operational coupling in order to generate synergy is considered in the contributions of Kamari et al. [7], Laszlo et al. [20], McCool [23], Adham et al. [25], and Wei et al. [28] and Barile et al. [71], who establish the importance of coherence between primary operations and strategic groups. However, the statistics obtained for this variable indicate that it is necessary to regulate the relationship between operational units, their management and coordination mechanisms considering the Env information in order to make the courses of action of the whole system homologous. Coordination (Crd) has also been dealt with in some contributions [17,21,29]; however, it was not identified that this function is part of the dynamics in RAMSAR sites from an integral vision and that complements the tasks of the management processes. In contrast, the proposed model suggests integrating control and regulatory mechanisms to mitigate environmental changes and allow operations at the sites under study to be congruent with the context in which they operate.

The contributions of Ni and Sun [33]; Svensson et al. [34] and Valdez-Juárez et al. [35] highlight the need to integrate comprehensive perspectives into the study of problems related to sustainability in protected areas. The results obtained for the variables OpM, Adt, Int and Plc indicate that in the RAMSAR sites where economic activities are carried out, management must support daily operations without neglecting the plans established by higher organisms, this will allow to positively indicate the achievement of sustainable performance without reducing effectiveness or efficiency.

Finally, and in coincidence with Wan Mohamed Radzi et al. [6], Aguayo and Eames [21], Boyle and Michell [22], Aranda-Usón et al. [29], and Xu et al. [36] it was identified that, although natural attributes confer distinctive and competitive advantages that can have a positive impact in economic terms on the communities of RAMSAR sites, in practice environmentally reactive plans and temporary solutions are implemented. In that sense, it is considered that the proposed relationships can propitiate continuous equilibrium in the organisations under study. In this context, it is worth mentioning that the current modality of management of the RAMSAR sites studied has certain characteristics, for example: the operations interfere with each other and are not organised in such a way that they can respond adequately to the requirements of their environment, low integration of technical elements and scarce management mechanisms. In this sense, the description of the VSM, which is proposed in this work, contrasts because it seeks to provide order and structure to the operation of these sites, and consider variables that can be understood and assimilated by all those who are related to the activities of RAMSAR. 
This article sought to propose an organisational model for RAMSAR sites based on the principles of organisational cybernetics. It is considered that the general objective was reached because, under the systemic method framework, methodological devices were joined that allowed for a different approach to the problem being taken. In this respect, the first particular objective of this study was fulfilled because the conjunction of these tools allowed framing the structural problems of the studied RAMSAR sites from the perspective of organisational cybernetics.

Following the statement of this proposal, the second objective was to outline a conceptual model that could be translated into VSM language for implementation. Consequently, the third objective of this study was to validate the construct using the PLS-PM by finding that the established relationships are statistically consistent and fit the context in which the participating organisations operate. Considering the results, it can be said that evidence was obtained that the environment (Env) includes more considerable significance in primary activities (Pac) or processes directly related to the organisational purpose. Consistent with what is established by organisational cybernetics, the PLS-PM showed that the relationship between the Pac and the elements of coordination, management, intelligence and policy development affect the ability to operate sustainably, as well as these relationships, affect the adaptive capacity and equilibrium of the system.

This made it possible to achieve the fourth objective since the application of PLS-PM allowed for the integration of the VSM to structure an organisational alternative for the RAMSAR sites as well as to rethink their relationships without bypassing the autonomy of the operational units and trying to enrich the communication and decision processes. It should be added that the use of a systemic perspective allowed for an understanding of structural pathologies that hinder the achievement of sustainable performance. Based on this, it is considered that the use of the systemic approach presents an area of opportunity to strengthen the management of protected areas, under an integral position to face the restrictions of the environment. This is essential because it allows these socio-ecological systems to increase their life cycle.

Finally, it is considered that the main contribution of this work is given in methodological terms by integrating systemic methodologies such as the VSM with statistical models to push forward their capabilities, as well as offering a new perspective to the use and validation of system thinking models and approaching problems with high incidence of the social factor, propitiating organisational schemes that reconcile productive relations and their environment without neglecting the purpose of an organisation. In conceptual terms, this article intends to pay attention to the study related to aspects of sustainable performance in the context of the RAMSAR sites since the identification of the variables that integrate the model can be useful because, as a whole, they consider operative, control, management and adaptation aspects in an organisation. Likewise, they can serve as a support for subsequent studies because they can be applied in different contexts and organisational levels. Also, it is expected that the ideas developed in this article have practical implications for the actors related with the management and operations of these type of areas. In this regard, the model suggests that their interactions can improve, considering the systems thinking approach as an alternative to the reductionist or functionalist perspective. In this sense, the systemic perspective of this proposal is not limiting and allows participants to use their own experience and add other managerial tools to reinforce courses of action.

Author Contributions: Authors in this article contributed equally to this work.

Funding: This research received no external funding.

Conflicts of Interest: The authors declare no conflict of interest.

\section{References}

1. He, Y.; He, P.; Xu, F.; Shi, C. (Victor) Sustainable tourism modeling: Pricing decisions and evolutionarily stable strategies for competitive tour operators. Tour. Econ. 2019, 25, 779-799. [CrossRef] 
2. Ramsar Convention Secretariat. An Introduction to the Ramsar Convention on Wetlands; Ramsar Convention Secretariat: Gland, Switzerland, 2016.

3. Gardner, R.C.; Barchiesi, S.; Beltrame, C.; Finlayson, C.M.; Galewski, T.; Harrison, I.; Paganini, M.; Perennou, C.; Pritchard, D.E.; Rosenqvist, A.; et al. State of the World's Wetlands and Their Services to People: A Compilation of Recent Analyses; Ramsar Convention Secretariat: Gland, Switzerland, 2015.

4. Ramsar Convention Secretariat. The List of Wetlands of International Importance; Ramsar Convention Secretariat: Gland, Switzerland, 2019.

5. Bansal, P.; DesJardine, M.R. Business sustainability: It is about time. Strateg. Organ. 2014, 12, 70-78. [CrossRef]

6. Wan Mohamed Radzi, C.; Salarzadeh Jenatabadi, H.; Hasbullah, M. Firm Sustainability Performance Index Modeling. Sustainability 2015, 7, 16196-16212. [CrossRef]

7. Kamari, A.; Jensen, S.R.; Corrao, R.; Kirkegaard, P.H. A Holistic Multi-Methodology for Sustainable Renovation. Int. J. Strateg. Prop. Manag. 2018, 23, 50-64. [CrossRef]

8. Gao, J.; Yu, Z.; Wang, L.; Vejre, H. Suitability of regional development based on ecosystem service benefits and losses: A case study of the Yangtze River Delta urban agglomeration, China. Ecol. Indic. 2019, 107, 105579. [CrossRef]

9. WTTC. Economic Impact of Travel E Tourism 2018: Mexico; WTTC: London, UK, 2018.

10. CNANP. Programa estatal de humedales costeros de Oaxaca; CNANP: Mexico City, Mexico, 2013.

11. Butler, C.; Adamowski, J. Empowering marginalized communities in water resources management: Addressing inequitable practices in Participatory Model Building. J. Environ. Manage. 2015, 153, 153-162. [CrossRef]

12. Demirel, P.; Kesidou, E. Sustainability-oriented capabilities for eco-innovation: Meeting the regulatory, technology, and market demands. Bus. Strateg. Environ. 2019, 28, 847-857. [CrossRef]

13. WTTC. Sustainability Reporting in Travel and Tourism; WTTC: London, UK, 2017.

14. Romero-García, L.E.; Aguilar-Gallegos, N.; Morales-Matamoros, O.; Badillo-Piña, I.; Tejeida-Padilla, R. Urban tourism: A systems approach-State of the art. Tour. Rev. 2019, 74, 679-693. [CrossRef]

15. Banson, K.E.; Nguyen, N.C.; Bosch, O.J.H. A Systems Thinking Approach to the Structure, Conduct and Performance of the Agricultural Sector in Ghana. Syst. Res. Behav. Sci. 2018, 35, 39-57. [CrossRef]

16. Van Dyk, D.J.; Pretorius, L. A Systems Thinking Approach To The Sustainability Of Quality Improvement Programmes. South African J. Ind. Eng. 2014, 25, 71. [CrossRef]

17. Fiksel, J. Meeting the Challenge of Sustainable Supply Chain Management. In Treatise on Sustainability Science and Engineering; Springer Netherlands: Dordrecht, The Netherlands, 2013; pp. 269-289.

18. Haywood, L.K.; Forsyth, G.G.; de Lange, W.J.; Trotter, D.H. Contextualising risk within enterprise risk management through the application of systems thinking. Environ. Syst. Decis. 2017, 37, 230-240. [CrossRef]

19. Nikolaou, I.; Evangelinos, K.; Leal Filho, W. A system dynamic approach for exploring the effects of climate change risks on firms' economic performance. J. Clean. Prod. 2015, 103, 499-506. [CrossRef]

20. Laszlo, A.; Laszlo, K.C.; Dunsky, H. Redefining success: Designing systemic sustainable strategies. Syst. Res. Behav. Sci. 2010, 27, 3-21. [CrossRef]

21. Aguayo, C.; Eames, C. Promoting community socio-ecological sustainability through technology: A case study from Chile. Int. Rev. Educ. 2017, 63, 871-895. [CrossRef]

22. Boyle, L.; Michell, K. A Management Concept for Driving Sustainability in Marginalised Communities in South Africa. Urban Forum 2018, 29, 185-204. [CrossRef]

23. McCool, S.F. Sustainable Tourism in an Emerging World of Complexity and Turbulence. In Reframing Sustainable Tourism; Springer Netherlands: Dordrecht, The Netherlands, 2016; pp. 3-11.

24. Barile, S.; Saviano, M. Complexity and Sustainability in Management: Insights from a Systems Perspective. In Social Dynamics in a Systems Perspective; Springer International Publishing: Cham, Switzerland, 2018; pp. 39-63.

25. Adham, K.A.; Muhamad, N.S.; Said, M.F.; Abdul Sarhadat, S.; Ismail, H.A.; Mohd Nasir, M.F.A. Diagnosing Business Incubation for Social Purpose: A Viable System Model Approach. Syst. Pract. Action Res. 2019, 32, 219-238. [CrossRef]

26. Bautista, S.; Espinoza, A.; Narvaez, P.; Camargo, M.; Morel, L. A system dynamics approach for sustainability assessment of biodiesel production in Colombia. Baseline simulation. J. Clean. Prod. 2019, 213, 1-20. [CrossRef] 
27. Song, M.; Wang, R.; Zeng, X. Water resources utilization efficiency and influence factors under environmental restrictions. J. Clean. Prod. 2018, 184, 611-621. [CrossRef]

28. Wei, T.; Lou, I.; Yang, Z.; Li, Y. A system dynamics urban water management model for Macau, China. J. Environ. Sci. 2016, 50, 117-126. [CrossRef]

29. Aranda-Usón, A.; Portillo-Tarragona, P.; Marín-Vinuesa, L.; Scarpellini, S. Financial Resources for the Circular Economy: A Perspective from Businesses. Sustainability 2019, 11, 888. [CrossRef]

30. Cheah, J.; Amran, A.; Yahya, S. Internal oriented resources and social enterprises' performance: How can social enterprises help themselves before helping others? J. Clean. Prod. 2019, 211, 607-619. [CrossRef]

31. Manab, N.A.; Aziz, N.A.A. Integrating knowledge management in sustainability risk management practices for company survival. Manag. Sci. Lett. 2019, 585-594. [CrossRef]

32. Yusoff, Y.M.; Omar, M.K.; Kamarul Zaman, M.D.; Samad, S. Do all elements of green intellectual capital contribute toward business sustainability? Evidence from the Malaysian context using the Partial Least Squares method. J. Clean. Prod. 2019, 234, 626-637. [CrossRef]

33. Ni, W.; Sun, H. The effect of sustainable supply chain management on business performance: Implications for integrating the entire supply chain in the Chinese manufacturing sector. J. Clean. Prod. 2019, 232, 1176-1186. [CrossRef]

34. Svensson, G.; Ferro, C.; Hogevold, N.; Padin, C.; Sosa Varela, J.C. Developing a theory of focal company business sustainability efforts in connection with supply chain stakeholders. Supply Chain Manag. An Int. J. 2018, 23, 16-32. [CrossRef]

35. Valdez-Juárez, L.; Gallardo-Vázquez, D.; Ramos-Escobar, E. CSR and the Supply Chain: Effects on the Results of SMEs. Sustainability 2018, 10, 2356. [CrossRef]

36. Xu, S.; Mingzhu, L.; Bu, N.; Pan, S. Regulatory frameworks for ecotourism: An application of Total Relationship Flow Management Theorems. Tour. Manag. 2017, 61, 321-330. [CrossRef]

37. Basavaraj, S.; Ravi, A.; Van Cranenburgh, K.; Vikkraman, P. CSR activities of a Japanese company operating in India-Strong or weak sustainability: A theory testing of a Cybernetic model. Int. J. Manag. Pract. 2018, 11, 284. [CrossRef]

38. Garrity, E.J. Tragedy of the Commons, Business Growth and the Fundamental Sustainability Problem. Sustainability 2012, 4, 2443-2471. [CrossRef]

39. Xing, K.; Ness, D.; Lin, F. A service innovation model for synergistic community transformation: Integrated application of systems theory and product-service systems. J. Clean. Prod. 2013, 43, 93-102. [CrossRef]

40. Bunge, M. Philosophy of Science and Technology: A Personal Report. In Philosophy of Latin America; Springer Netherlands: Dordrecht, The Netherlands, 2003; ISBN 9027719039.

41. Jerardino-Wiesenborn, B.; Paucar-Caceres, A.; Ochoa-Arias, A. A Conceptual Framework Based on Maturana's Ontology of the Observer to Explore the Checkland's Soft Systems Methodology. 2019. Available online: https://link.springer.com/article/10.1007/s11213-019-09502-y (accessed on 9 September 2019).

42. Beer, S. Diagnosing the System for the Organization; John Wiley \& Sons: London, UK, 1985.

43. Warfield, J. The Domain of Science Model: Extensions and Restrictions. 1987. Available online: http://mars.gmu.edu/jspui/bitstream/handle/1920/3303/Warfield_35_14_A1b.pdf?sequence=1 (accessed on 28 September 2009).

44. Warfield, J. A proposal for systems science. Syst. Res. Behav. Sci. 2003, 20, 507-520. [CrossRef]

45. Mouhib, N.; Bah, S.; Berrado, A. Viability Theory and PSI Theory Interrelation Inspired by Bunge Systemic Classification: The Viable System Ontology Theory. 2019. Available online: https://ink.springer.com/article/ 10.1007\%2Fs11213-019-09503-x (accessed on 30 september 2019).

46. Soto, M.; Rojas, O. Self-efficacy and job satisfaction as antecedents of citizenship behaviour in private schools. Int. J. Manag. Educ. 2019, 13, 82. [CrossRef]

47. Cardoso Castro, P.P. The viable system model as a framework to guide organisational adaptive response in times of instability and change. Int. J. Organ. Anal. 2019, 27, 289-307. [CrossRef]

48. Cardoso Castro, P.P.; Espinosa, A. Identification of organisational pathologies. Kybernetes 2019. [CrossRef]

49. Espinosa, A. Governance for sustainability: Learning from VSM practice. Kybernetes 2015, 44, 955-969. [CrossRef]

50. 50 Núñez Ríos, J.E.; Sánchez Garcí, J.Y.; Tejeida Padilla, R.; Coria Páez, A.L. Perspectiva sistémica en los procesos de capital humano en PyMEs orientadas al servicio de hospedaje. Nov. Sci. 2018, 10, 481. [CrossRef] 
51. Núñez-Ríos, J.E.; Sánchez-García, J.Y.; Tejeida-Padilla, R. Human Capital Management in Tourism SMEs from a Cyber-Systemic Approach. Syst. Pract. Action Res. 2019. [CrossRef]

52. Panagiotakopoulos, P.D.; Espinosa, A.; Walker, J. Sustainability management: Insights from the Viable System Model. J. Clean. Prod. 2016, 113, 792-806. [CrossRef]

53. Preece, G.; Shaw, D.; Hayashi, H. Using the Viable System Model (VSM) to structure information processing complexity in disaster response. Eur. J. Oper. Res. 2013, 224, 209-218. [CrossRef]

54. Preece, G.; Shaw, D.; Hayashi, H. Application of the Viable System Model to analyse communications structures: A case study of disaster response in Japan. Eur. J. Oper. Res. 2015, 243, 312-322. [CrossRef]

55. Sánchez-García, J.Y.; Núñez-Ríos, J.E.; Badillo-Piña, I. Innovation in services: A viable system model design for tourist MSMES integration in México. In Proceedings of the 62nd Annual Meeting of the International Society for the Systems Sciences, ISSS 2018: Innovation and Optimization in Nature and Design, Couvallis, OR, USA, 22-27 July 2018; Volume 1, pp. 141-153.

56. Stich, V.; Groten, M. Design and Simulation of a Logistics Distribution Network Applying the Viable System Model (VSM). Procedia Manuf. 2015, 3, 534-541. [CrossRef]

57. Tanaka, H. A Viable System Model Reinforced by Meta Program Management. Procedia Soc. Behav. Sci. 2013, 74, 377-387. [CrossRef]

58. Barba-Sánchez, V.; Atienza-Sahuquillo, C. Environmental Proactivity and Environmental and Economic Performance: Evidence from the Winery Sector. Sustainability 2016, 8, 1014. [CrossRef]

59. Schwaninger, M. Systemic design for sustainability. Sustain. Sci. 2018, 13, 1225-1234. [CrossRef]

60. Troncale, L. Towards a science of systems. Syst. Res. Behav. Sci. 2006, 23, 301-321. [CrossRef]

61. Sanchez, G. PLS Path Modeling with R Trowchez Editions. Available online: http://www.gastonsanchez. com/PLSPathModelingwithR.pdf. (accessed on 10 August 2019).

62. Hair, J.F.; Risher, J.J.; Sarstedt, M.; Ringle, C.M. When to use and how to report the results of PLS-SEM. Eur. Bus. Rev. 2019, 31, 2-24. [CrossRef]

63. Kock, N. Minimum Sample Size Estimation in PLS-SEM: An Application in Tourism and Hospitality Research. In Applying Partial Least Squares in Tourism and Hospitality Research; Faizan, A., Mostafa Rasoolimanesh, S., Cobanoglu, C., Eds.; Emerald Publishing Limited: Bingley, UK, 2018; p. 264. ISBN 9781787567009.

64. Marcoulides, G.A.; Chin, W.W. Marcoulides; Chin; Saunders A Critical Look at Partial Least Squares Modeling. MIS Q. 2009, 33, 171. [CrossRef]

65. Esposito Vinzi, V.; Chin, W.W.; Henseler, J.; Wang, H. (Eds.) Handbook of Partial Least Squares; Springer Berlin Heidelberg: Berlin/Heidelberg, Germany, 2010; ISBN 978-3-540-32825-4.

66. Marin-Garcia, J.; Alfalla-Luque, R. Key issues on Partial Least Squares (PLS) in operations management research: A guide to submissions. J. Ind. Eng. Manag. 2019, 12, 219. [CrossRef]

67. Fornell, C.; Larcker, D.F. Evaluating Structural Equation Models with Unobservable Variables and Measurement Error. J. Mark. Res. 1981, 18, 39. [CrossRef]

68. Villanueva-Álvaro, J.-J.; Mondéjar-Jiménez,J.; Sáez-Martínez, F.-J. Rural Tourism: Development, Management and Sustainability in Rural Establishments. Sustainability 2017, 9, 818. [CrossRef]

69. Núñez, J.E.; Briones, A.; Sánchez, J.; Castillo, O.; Arenas, T.; Tejeida, R. Towards an autopoietic management of human activity systems in mexican tourism sector smes. Proc. 59th Annu. Meet. ISSS 2015, 1, 1-16.

70. Espejo, R.; Reyes, A. Organizational Systems; Springer Berlin Heidelberg: Berlin/Heidelberg, Germany, 2011; ISBN 978-3-642-19108-4.

71. Barile, S.; Pellicano, M.; Polese, F. (Eds.) Social Dynamics in a Systems Perspective; New Economic Windows; Springer International Publishing: Cham, Switzerland, 2018; ISBN 978-3-319-61966-8.

(C) 2019 by the authors. Licensee MDPI, Basel, Switzerland. This article is an open access article distributed under the terms and conditions of the Creative Commons Attribution (CC BY) license (http://creativecommons.org/licenses/by/4.0/). 